\begin{tabular}{cc}
\hline International Journal of Physical Research, $7(1)(2019) 1-2$ \\
SPC \\
Website: $w w w . s c i e n c e p u b c o . c o m / i n d e x . p h p / I J P R$ \\
Short communication
\end{tabular}

\title{
Is there a possibility of perovskite taking over the solar technology market by 2030 ?
}

\author{
Adebayo A. Fashina ${ }^{1,2,3 *}$ \\ ${ }^{1}$ Department of Mathematics and Natural Sciences, Tubman University, P. O. Box 3570, Harper City, Maryland County, Liberia \\ ${ }^{2}$ School of Graduate Studies and Research, Gollis University, Koudbuur District, Hargeisa, Somaliland \\ ${ }^{3}$ Department of Engineering Management, Gollis University, Koudbuur District, Hargeisa, Somaliland \\ *Corresponding author E-mail: adebayofashina@gmail.com
}

\begin{abstract}
In recent time, there have been enormous advances in the development of perovskite solar cells in terms of its efficiency, rising from 3.8 percent in 2009 to 23.7 percent in 2018. This took other solar technologies over thirty years of research to accomplish. On the other hand, perovskite proffers a more affordable solution since it is potentially much cheaper to produce and relatively simple to manufacture than silicon solar cells. In spite of this great potential, perovskite solar cell technology is still in the premature stages of commercialization due to a number of concerns. Moreover, like with many new technologies, there is a difference between what works in the laboratory at smallscale and in the factory at large-scale. Thus, looking at perovskites as a material, it has the tendency to be a bit unstable at high temperature and susceptible to moisture and these could cause the decomposition of cells. The question here is: can perovskite outshine silicon solar cel1s in the next 10 years considering the successes so far and the vigorous research that is presently taking place globally?
\end{abstract}

Keywords: Perovskite; Silicon Solar Cell; Tandem Cells; Efficiency; Commercialization.

\section{Introduction}

Solar energy has long been considered as one of the most sustainable strategies for decarbonisation [1]. However, the solar cell technologies that are required to convert solar energy into electricity have to be efficient, cost effective and must have a long lifespan before it can be put forward for commercialization. Presently, crystalline silicon-based solar cells with relatively high efficiency of about 22 percent accounts for a large portion of the solar panels sold in the world [2]. Although, silicon is in abundant as a raw material used for these solar cells, its processing appears to be complicated and thus increases the manufacturing costs, making the end-product to be quite expensive. Furthermore, the increasing need for clean energy sources alongside the high cost of silicon solar cells has led to an ardent search for an alternative material that can cause a major change in the solar technology industry. About a decade ago, perovskite was discovered to be the idea material suitable to fill in this gap.

Perovskite solar cells comprise of a perovskite structured compound, mainly a hybrid organic-inorganic lead or tin halide-based material that serves as the light-harvesting active layer [3]. It displays a number of thrilling properties that makes it an attractive contender for enabling cost-effective and highly efficient photovoltaics (PV) cells that have different applications.

Basically, perovskites have intrinsic properties such as broad absorption spectrum, long transport distance of holes and electrons, fast charge separation, long carrier separation lifetime etc. Unlike silicon solar cells that produce electricity by the absorption of photons of visible and infrared light, perovskite cells generate electricity from different wavelengths of light, particularly, in the visible spectrum and consequently harvests more power per photon of light than silicon cells. This is a huge advantage that perovskite solar cells have over the traditional solar technology.

Generally, solar cells are multi-layered structures, but what makes perovskites unique is that they are amendable to printing and can be entrenched into various types of structures like rooftops and windows to capture solar energy. It also has the potential to play a vital role in the future development of batteries for electric vehicles, lasers and sensors. Besides, perovskite-based solar cells proffer some features such as flexibility, semi-transparency, flimsyweight etc. which researchers and players in the solar industry logically believe will unveil several applications for solar cells in the future.

Although perovskite solar cells are yet to access the solar technology market, progress towards commercialization appears to be promising, and many believe that within the next decade perovskite solar technology would materialize as the factual alternative to silicon-based panels. This is because the impressive rise in its efficiency from $3.8 \%$ in 2009 to $22.7 \%$ in 2017/18 is seen to be important and inspiring, and this appears to be progressing in laboratories across the globe (See Figure 1) [4]. Currently, perovskite is believed to be the rising star of solar energy technology and have drawn a huge interest among the research and academic communities.

Despite the fact that the opportunity to explore the use of perovskites, is gaining global attention, this important material is still faced with quite a few challenges. The major concerns are related to the problem of overall cost, the issue of toxicity, cell stability and the associated scaling-up potential. First, the main reason why the overall cost of perovskite is presently considered as a challenge is because the major electrode material used in perovskite solar cell is gold. 


\section{Number of publications}

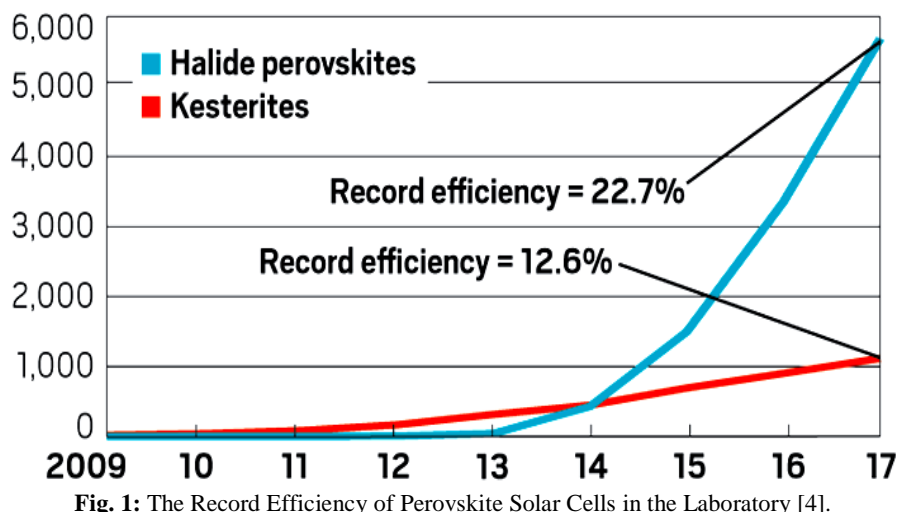

Another reason is that perovskite solar cells that are cheaper do have short lifespan due to the rapidly deterioration of the cells in presence of moisture. Perovskite cells are known to be susceptible to humidity, intense light, temperature and weather change. These are factors that cause the decomposition of cells. As a result, the cells presently only function outdoor for a few months to a year unlike the silicon solar cells that are durable (up to 25 years). Moreover, introducing heavy encapsulation to protect perovskite could increase the overall cost and weight of the device [5].

Secondly, the cheaper perovskites that are presently being used contain lead, which is a substantial pollutant and thus, raises environmental and long-term stability concerns. Likewise, some of the breakdown products of perovskite are known to be toxic and there are predictions that this might be carcinogenic. At present, the solar research community are vigorously working out ways to develop non-toxic alternatives such as tin which have achieved a cell efficiency of about $6 \%$ and can surely be improved upon [4].

Lastly, another issue relates to the scaling up potential of perovskite solar cells. Currently, reports from laboratory testing of small cells $\left(<1 \mathrm{~cm}^{2}\right)$ have achieved high efficiency rating. Yet, the cell size is suggested to be quite small for real solar panel [4, 5].

To this end, many research groups are presently working towards overcoming these challenges and even some companies are believed to be running in the direction of commercializing perovskite solar technology in the nearest future. In particular, researchers are now exploring the possible ways of merging perovskites with other technologies like silicon and copper indium gallium diselenide (CIGS), in order to create what is known as the "tandem cells" [6]. Tandem cells are presently being optimised to capture discrete parts of the solar spectrum, and thus can attain yet higher efficiencies [7]. Furthermore, stacking a perovskite cell on top of low-quality silicon cells promises to be a comparatively cheap process and has exceeded a cell efficiency of $25 \%$ in the laboratory [8]. Some groups have at this point built a working model of perovskite PV modules that contains several solar cells that are larger than the experimental prototype and to a great extent smaller than the required size for commercialization [9]. The researchers believe that despite the reduction of the cell efficiency from $20 \%$ to $15 \%$ as a result of the scaling-up process, there would be some major improvements in the coming years that will pave way for commercialization [9]. The big question then is "how soon would this happen?"

In my opinion, if the above challenges of increasing efficiency and stability, prolonging cell lifetime and replacing toxic materials with safer ones can be prevailed over, then stand-alone perovskite solar cells will have the possibility of changing the economics of solar power in the next decade. This is because the production of perovskite cells is far cheaper when compared to silicon cells. This possibly might be a way for this novel material to cut in on the silicondominated market. However, this can only be made possible via a thorough analysis of the device architecture, properties of the materials, regulatory procedures for solar cells etc. On the other hand, by leveraging the existing silicon factories around the globe, making module from tandem cells will be relatively cheap and achievable. In addition, based on the fact that tandem cells possess huge application in terms of rooftop panels, it is likely that it turns out to be a bigger industry soon.

To conclude, the realization of perovskite solar cells that are feasible for industrialization will be a very exciting development that could revolutionize the world in the nearest future. Although, it is quite difficult to forecast if this would happen by 2030, but one thing is sure that perovskites cells will not just penetrate the silicon-based PV market completely at once.

\section{References}

[1] Fashina, A.; Mundu, M.; Akiyode, O.; Abdullah, L.; Sanni, D.; Ounyesiga, L. The Drivers and Barriers of Renewable Energy Applications and Development in Uganda: A Review. Clean Technologies 2018, 1(1), 9-39. https://doi.org/10.3390/cleantechnol1010003.

[2] Fashina, A. A.; Adama, K. K.; Abdullah, L. A.; Ani, C. J.; Oyewole, O. K.; Asare, J.; Anye, V. C. Atomic Force Microscopy Analysis of Alkali Textured Silicon Substrates for Solar Cell Applications. Int. J. Phy. Research 2018 6(1), 13-17. https://doi.org/10.14419/ijpr.v6i1.8795.

[3] Manser J. S.; Christians J. A.; Kamat P.V. Intriguing Optoelectronic Properties of Metal Halide Perovskites. Chemical Reviews, 2016116 (21), 12956-13008. https://doi.org/10.1021/acs.chemrev.6b00136.

[4] Chen, Y.; Zhang, L.; Zhang, Y.; Gao, H.; Yan, H. large-area Perovskite Solar Cells-A Review of Recent Progress and Issues. RSC Advances, 2018 8(19), 10489-10508. https://doi.org/10.1039/C8RA00384J.

[5] Mertens R.; Peleg R. Perovskite Solar, Perovskite-Info, available at: https://www.perovskite-info.com/perovskite-solar

[6] Rühle S. The Detailed Balance Limit of Perovskite/Silicon and Perovskite/CdTe Tandem Solar Cells. Physica Status Solidi (a) 2017 214(5), 1600955. https://doi.org/10.1002/pssa.201600955.

[7] Sanni, D.M.; Chen, Y.; Yerramilli, A.S.; Ntsoenzok, E.; Asare, J.; Adeniji, S.A.; Oyelade, O.V.; Fashina, A.A.; Alford, T.L. An approach to optimize pre-annealing aging and anneal conditions to improve photovoltaic performance of perovskite solar cells. Materials for Renewable and Sustainable Energy, 2019 8(1), 3-12 https://doi.org/10.1007/s40243-018-0139-3.

[8] Service R.F. Perovskite solar cells gear up to go commercial, Science, 9 December 2016 354(6317), 1214-1215; available at: http://science.sciencemag.org/content/354/6317/1214.full. https://doi.org/10.1126/science.354.6317.1214.

[9] Liu, Z.; Qiu, L.; Juarez-Perez, E.J.; Hawash, Z.; Kim, T.; Jiang, Y.; Wu, Z.; Raga, S.R.; Ono, L.K.; Liu, S.F.; Qi, Y. Gas-solid Reaction Based over One-Micrometer thick Stable Perovskite Films for Efficient Solar Cells and Modules. Nature Communications, 2018; 9(1), 3880. https://doi.org/10.1038/s41467-018-06317-8. 